\title{
Papers
}

\section{Low consumption of seafood in early pregnancy as a risk factor for preterm delivery: prospective cohort study}

Sjúrður Fróði Olsen, Niels Jørgen Secher

\begin{abstract}
Objective To determine the relation between intake of seafood in pregnancy and risk of preterm delivery and low birth weight.

Design Prospective cohort study.

Setting Aarhus, Denmark.

Participants 8729 pregnant women.

Main outcome measures Preterm delivery and low birth weight.

Results The occurrence of preterm delivery differed significantly across four groups of seafood intake,

falling progressively from $7.1 \%$ in the group never consuming fish to $1.9 \%$ in the group consuming fish as a hot meal and an open sandwich with fish at least once a week. Adjusted odds for preterm delivery were increased by a factor of 3.6 (95\% confidence interval 1.2 to 11.2 ) in the zero consumption group compared with the highest consumption group. Analyses based on quantified intakes indicated that the working range of the dose-response relation is mainly from zero intake up to a daily intake of $15 \mathrm{~g}$ fish or $0.15 \mathrm{~g} \mathrm{n}-3$ fatty acids. Estimates of risk for low birth weight were similar to those for preterm delivery.

Conclusions Low consumption of fish was a strong risk factor for preterm delivery and low birth weight. In women with zero or low intake of fish, small amounts of n-3 fatty acids - provided as fish or fish oil-may confer protection against preterm delivery and low birth weight.
\end{abstract}

\section{Introduction}

It is important to identify modifiable causes of preterm delivery and fetal growth retardation, which are strong predictors of infants' later health and survival. Observations of high birth weights ${ }^{1}$ and long gestations ${ }^{2}$ in the fish eating community of the Faroe Islands suggested that intake of seafood rich in long chain n-3 fatty acids can increase birth weight by prolonging gestation ${ }^{2}$ or by increasing the fetal growth rate. ${ }^{3-6}$

Fish oil has been shown in randomised trials ${ }^{78}$ and animal experiments ${ }^{9}{ }^{10}$ to have the potential to delay spontaneous delivery and prevent preterm delivery, but the minimum amount of $\mathrm{n}-3$ fatty acids needed to obtain this effect remains to be determined. No detectable effects on fetal growth rate were seen in these trials, ${ }^{78}$ but fish oil was provided only in the second half of pregnancy, and several observational studies have found direct associations between measures of seafood intake in pregnancy and fetal growth rate..$^{51-14}$

We investigated these issues in a cohort of women in whom seafood intake in early pregnancy was assessed prospectively by a questionnaire method. ${ }^{15} \mathrm{We}$ tested whether a low intake of seafood in early pregnancy is a risk factor for preterm delivery and low birth weight and whether it is associated with a lower fetal growth rate. We related the findings to quantified intakes of fish and long chain n-3 fatty acids.

\section{Methods}

We invited all pregnant women receiving routine antenatal care in Aarhus, Denmark, to complete self administered questionnaires in weeks 16 and 30 of gestation. The study base has been described in detail elsewhere ${ }^{16}$ During 1992-6 the questionnaire administered at 16 weeks contained questions about intake of fish and fish oil. Only singleton, live born babies without detected malformations were included in the analysis. The local scientific-ethical committee approved the protocol, and we used an informed consent form.

\section{Exposure variables}

In Denmark fish is eaten mainly as part of a hot meal, in an open sandwich, or cold in a green salad or pasta salad. ${ }^{15}$ Frequency of consumption of such meals has been shown to be a strong and independent predictor of variation in erythrocyte n-3 fatty acids, without taking into consideration whether the meals contained fat or lean fish. ${ }^{15}$ We posed four questions: "How often did you eat: $(a)$ fish in a hot meal, $(b)$ bread with fish, $(c)$ green salad or pasta salad with fish, and $(d)$ fish oil as a supplement?" The women were asked to understand the term "fish" as including roe, prawn, crab, and mussel and to let the responses represent the period from when they first knew they were pregnant until completion of the questionnaire. Each question had six predefined response categories: never, less than once a month, 1-3 times a month, 1-2 times a week, 3-6 times a week, every day.

We quantified daily intakes of fish and long chain n-3 fatty acids on the basis of the following assumptions. (Contribution of long chain n-3 fatty aids from foods of non-marine origin-for example, offal meat-was considered negligible.) The six frequency

\section{Maternal Nutrition Group, Danish Epidemiology Science Centre, Statens Serum Institut, Artillerivej 5, DK-2300 Copenhagen S, Denmark \\ Sjúrður Fróði Olsen associate professor \\ Perinatal \\ Epidemiology Research Unit, Department of Obstetrics and Gynaecology, Skejby University Hospital, DK-8200 Aarhus N, Denmark Niels Jørgen Secher professor \\ Correspondence to: S F Olsen}

sfo@ssi.dk

BMJ 2002;324:1-5 
Table 1 Frequency of consumption of meals containing fish by 8729 women. Values are number (percentage). Women who took fish oil were excluded

\begin{tabular}{lccccrrr} 
Meal type & Never & $<$ per month & 1-3 per month & 1-2 per week & 3-6 per week & Every day & Total \\
\hline Hot meal & $999(11.4)$ & $2700(30.9)$ & $3851(44.1)$ & $1140(13.1)$ & $32(0.4)$ & 0 & $8722(100)$ \\
\hline Sandwich & $601(6.9)$ & $1425(16.3)$ & $3196(36.6)$ & $2698(30.9)$ & $711(8.1)$ & $92(1.1)$ & $8723(100)$ \\
\hline Salad & $3515(40.3)$ & $3111(35.7)$ & $1766(20.2)$ & $299(3.4)$ & $24(0.3)$ & $4(0.0)$ & $8719(100)$ \\
\hline
\end{tabular}

categories corresponded to $0,0.5,2,4,20$, and 28 servings per 28 days. Each serving of a hot fish meal provided $144 \mathrm{~g}$ fish and $1627 \mu \mathrm{g}$ n-3 fatty acids, a fish sandwich provided $29 \mathrm{~g}$ fish and $431 \mu \mathrm{g} \mathrm{n}-3$ fatty acids, and a fish salad provided $50 \mathrm{~g}$ fish and $149 \mu \mathrm{g} \mathrm{n}-3$ fatty acids. These values were mainly derived from work done by the Danish Veterinary and Food Administration on portion sizes, distributions of fish species in meals, and food tables for the Danish population. ${ }^{17} 18$ We defined six groups of exposure, with the lowest group consuming no fish and the other five groups being fifths of the remaining participants (designated QUANT0, QUANT1, QUANT2, QUANT3, QUANT4, QUANT5).

To avoid the uncertainties of the above assumptions we adopted a priori an alternative analytical strategy, which was based solely on the raw food frequency variables ("food frequency strategy"), and which could still provide a strong test of the hypotheses. To limit the number of variables considered simultaneously, we restricted analyses to the 1304 women who had eaten no fish salad and who had consumed hot meals and open sandwiches with fish with the same frequency. To secure substantial exposure contrasts, we defined four comparison groups with reasonable sample sizes in such a way that both the defining variables increased progressively: women who had consumed fish as a hot meal and as open sandwiches $(a)$ zero times, $(b)$ more than zero but less than once a month, $(c)$ 1-3 times a month, and $(d)$ once or more often a week (designated FREQ0, FREQ1, FREQ2, and FREQ3).

\section{Outcome variables}

We assessed gestational age by early ultrasonography in $71 \%$ of participants, and otherwise from menstrual data or best clinical judgment. We defined low birth weight as $<2500 \mathrm{~g}$ and preterm as delivery before 259 days. We assessed intrauterine growth retardation below the 10th centile and birth weight expected from gestational age from the infant's birth weight, gestational age, and sex, on the basis of a Danish standard. ${ }^{19}$

\section{Covariates}

We used covariates as previously described ${ }^{16}:$ sex of infant (girl, boy); smoking ( $0,1-9, \geqslant 10$ cigarettes a day) and alcohol consumption ( $<10$ or $\geqslant 10$ drinks a week) in pregnancy; maternal age $(\leqslant 19,20-29,30-39, \geqslant 40$ years), parity $(0, \geqslant 1)$, height $(\leqslant 159,160-169,170-179$, $\geqslant 180 \mathrm{~cm})$, and pre-pregnant weight $(\leqslant 49,50-59$, $60-69,70-79, \geqslant 80 \mathrm{~kg})$; length of education $(\leqslant 7,8-9$, $\geqslant 10$ years); and whether the mother had a cohabitant $(0,1)$.

\section{Statistical analyses}

The study hypothesis could be tested in many different ways with our data, so we decided all analytical conditions a priori. This avoided data dependent analyses and kept preconditions for interpreting $\mathrm{P}$ values and confidence intervals as valid as possible for an observational study with self selected rather than randomised allocation to levels of exposure. We used the $\chi^{2}$ test, analysis of variance, and logistic regression. We included all suspected potential confounders (see covariate list) in the multivariate model simultaneously.

Table 2 Occurrences of low birth weight, preterm delivery, and intrauterine growth retardation, and mean birth weight, gestation length, and birth weight adjusted for gestation length, according to quantified daily intake of long chain n-3 fatty acids

\begin{tabular}{|c|c|c|c|c|c|c|}
\hline \multirow[b]{2}{*}{ Group* } & \multicolumn{3}{|c|}{ Dichotomous outcomes (№ (\%)) } & \multicolumn{3}{|c|}{ Continuous outcomes (mean (SD)) } \\
\hline & $\begin{array}{l}\text { Low birth } \\
\text { weight }\end{array}$ & Preterm delivery & $\begin{array}{l}\text { Intrauterine growth } \\
\text { retardation }\end{array}$ & Birth weight $(g)$ & Gestation (days) & $\begin{array}{l}\text { Adjusted birth } \\
\text { weight (g) }\end{array}$ \\
\hline$\overline{\text { QUANTO }(\mathrm{n}=282)}$ & $20(7.1)$ & $20(7.1)$ & $23(8.2)$ & $3432(589)$ & $278.8(14.3)$ & $3466(490)$ \\
\hline QUANT1 $(n=1723)$ & $54(3.1)$ & $71(4.1)$ & $152(8.8)$ & $3543(543)$ & $281.7(11.9)$ & $3494(486)$ \\
\hline QUANT2 $(n=1618)$ & $52(3.2)$ & $61(3.8)$ & $116(7.2)$ & $3572(559)$ & $281.8(12.4)$ & 3521 (481) \\
\hline QUANT3 $(\mathrm{n}=1890)$ & $34(1.8)$ & $45(2.4)$ & $96(5.1)$ & 3592 (498) & $282.2(10.4)$ & $3532(446)$ \\
\hline QUANT4 $(n=1419)$ & $35(2.5)$ & $50(3.5)$ & $91(6.4)$ & 3581 (521) & $282.2(11.3)$ & $3520(455)$ \\
\hline QUANT5 ( $\mathrm{n}=1775)$ & $37(2.1)$ & $52(2.9)$ & $94(5.3)$ & 3617 (518) & $282.4(11.0)$ & $3550(457)$ \\
\hline \multicolumn{7}{|l|}{ Statistical tests } \\
\hline Between groups ( $\mathrm{P}$ value) & $<0.001 \dagger$ & $0.001 \dagger$ & $0.001 \dagger$ & $0.001 \ddagger$ & $0.001 \neq$ & $0.004 \ddagger$ \\
\hline Linear trend ( $\mathrm{P}$ value) & $<0.001$ & 0.003 & 0.001 & 0.001 & 0.001 & 0.001 \\
\hline
\end{tabular}

${ }^{*}$ See text for definitions of the six groups. †Pearson $\chi^{2}$. †Analysis of variance.

Table 3 Occurrences of potential confounders according to quantified daily intake of long chain n-3 fatty acids. Values are percentages (numbers)

\begin{tabular}{llllllll} 
Group* & \multicolumn{1}{c}{ Smoker } & \multicolumn{1}{c}{ High school } & Primiparous & Single & $<\mathbf{5 0}$ kg & $<1.6$ m & Teenager \\
\hline QUANT0 & $40.7(112 / 275)$ & $34.2(92 / 269)$ & $58.5(165 / 282)$ & $7.6(21 / 276)$ & $6.5(18 / 275)$ & $10.1(27 / 268)$ & $6.7(19 / 282)$ \\
\hline QUANT1 & $30.2(508 / 1683)$ & $44.1(736 / 1669)$ & $59.3(1022 / 1723)$ & $5.8(98 / 1697)$ & $5.2(88 / 1700)$ & $7.7(131 / 1695)$ & $1.9(32 / 1723)$ \\
\hline QUANT2 & $23.0(363 / 1576)$ & $56.2(876 / 1560)$ & $56.4(912 / 1618)$ & $4.9(78 / 1593)$ & $4.7(75 / 1590)$ & $6.2(99 / 1604)$ & $1.2(19 / 1618)$ \\
\hline QUANT3 & $19.0(353 / 1851)$ & $67.3(1244 / 1849)$ & $50.6(956 / 1890)$ & $3.9(72 / 1865)$ & $3.1(57 / 1861)$ & $5.1(94 / 1861)$ & $0.3(6 / 1890)$ \\
\hline QUANT4 & $21.1(293 / 1391)$ & $67.4(931 / 1382)$ & $47.9(680 / 1419)$ & $2.7(38 / 1395)$ & $3.3(46 / 1399)$ & $6.1(85 / 1399)$ & $0.6(8 / 1419)$ \\
\hline QUANT5 & $18.3(315 / 1724)$ & $69.9(1201 / 1719)$ & $49.6(880 / 1775)$ & $4.5(78 / 1741)$ & $4.2(73 / 1749)$ & $5.7(100 / 1748)$ & $0.4(7 / 1775)$ \\
\hline
\end{tabular}

${ }^{*}$ See text for definitions of the six groups. 


\section{Results}

Of 8998 women returning the 16 week questionnaire, 8729 (97\%) had not consumed fish oil supplementsresults refer to this restricted group. Mean birth weight was 3577 (SD 531) g, and duration of gestation was 280.0 (11.5) days. Low birth weight occurred in 2.7\% (232/8707), preterm delivery in $3.4 \%(299 / 8707)$, and intrauterine growth retardation in $6.6 \%(572 / 8705)$ of participants. Table 1 shows unidimensional distributions of the three food frequency variables. On average, women consumed 15.8 (SD 13.9) g fish and 0.182 (0.161) $\mathrm{g}$ long chain n-3 fatty acids a day. Covariate distributions, assessed in a larger sample from the same population, have been published. ${ }^{16}$

Estimated mean daily intakes for the six exposure groups QUANT0 to QUANT5 were 0, 3.3, 8.0, 13.4, 18.0, and $38.4 \mathrm{~g}$ fish; and 0, 0.038, 0.092, 0.146, 0.216, and $0.445 \mathrm{~g}$ long chain $\mathrm{n}-3$ fatty acids. Low birth weight, preterm birth, and intrauterine growth retardation all tended to decrease with increasing fish consumption, and mean birth weight, duration of gestation, and birth weight adjusted for gestational age tended to increase with increasing fish consumption (table 2). These associations were mainly apparent at the lower end of the exposure scale-this was particularly the case for preterm birth and mean duration of gestation.

Smokers, primiparous women, teenagers, and women with low weight, short stature, and without high school education and cohabitant occurred more frequently in the low exposure groups (table 3). The impression that the decline in risk occurred mainly at the lower end of the exposure distribution was confirmed on examination of adjusted odds ratios for low birth weight and preterm birth, with the highest intake group (QUANT5) as reference (table 4). The association between intake of fish and risk of fetal growth retardation weakened but was not always fully abolished after adjustment for potential confounding.

\section{Alternative strategy}

Table 5 defines the comparison groups of the food frequency strategy. Estimated mean daily intakes in the four groups FREQ0 to FREQ3 were 0, 3.1, 12.4, and $44.3 \mathrm{~g}$ fish; and $0,0.037,0.147$, and $0.537 \mathrm{~g}$ long chain n-3 fatty acids. Occurrence of low birth weight and preterm delivery both decreased significantly and progressively across the four groups, as frequency of fish consumption increased (table 6). Intrauterine growth retardation exhibited a similar, but non-significant, pattern. Mean birth weight, duration of gestation, and
Table 4 Crude and adjusted ${ }^{*}$ odds ratios $(95 \% \mathrm{Cl})$ for low birth weight, preterm delivery, and intrauterine growth retardation according to quantified daily intake of long chain $n-3$ fatty acids $(n=7902)$. The highest intake group (QUANT5) is used as reference

\begin{tabular}{|c|c|c|c|}
\hline Groupt & Low birth weight & Preterm delivery & $\begin{array}{l}\text { Intrauterine growth } \\
\text { retardation }\end{array}$ \\
\hline \multicolumn{4}{|l|}{ QUANTO: } \\
\hline Crude & 4.37 (2.43 to 7.87$)$ & 2.95 (1.67 to 5.20$)$ & 1.52 (0.91 to 2.55 ) \\
\hline Adjusted & 3.22 (4.73 to 6.00$)$ & 2.69 (1.49 to 4.84$)$ & 1.14 (0.67 to 1.98$)$ \\
\hline \multicolumn{4}{|l|}{ QUANT1: } \\
\hline Crude & 1.61 (1.02 to 2.55$)$ & 1.61 (1.09 to 2.37$)$ & 1.73 (1.31 to 2.28$)$ \\
\hline Adjusted & $1.31(0.82$ to 2.10$)$ & 1.48 (0.99 to 2.21$)$ & 1.45 (1.09 to 1.94$)$ \\
\hline \multicolumn{4}{|l|}{ QUANT2: } \\
\hline Crude & 1.69 (1.07 to 2.68$)$ & 1.48 (0.99 to 2.21$)$ & 1.41 (1.05 to 1.90$)$ \\
\hline Adjusted & 1.54 (0.97 to 2.46$)$ & 1.44 (0.96 to 2.16$)$ & 1.31 (0.97 to 1.77$)$ \\
\hline \multicolumn{4}{|l|}{ QUANT3: } \\
\hline Crude & 0.98 (0.60 to 1.61$)$ & 0.90 (0.59 to 1.38$)$ & 1.02 (0.76 to 1.38$)$ \\
\hline Adjusted & $0.99(0.60$ to 1.63$)$ & 0.90 (0.59 to 1.39$)$ & 1.03 (0.76 to 1.40$)$ \\
\hline \multicolumn{4}{|l|}{ QUANT4: } \\
\hline Crude & $1.12(0.67$ to 1.88$)$ & $1.28(0.83$ to 1.96$)$ & $1.16(0.85$ to 1.59$)$ \\
\hline Adjusted & 1.16 (0.69 to 1.94$)$ & 1.31 (0.85 to 2.01$)$ & 1.25 (0.91 to 1.72$)$ \\
\hline \multicolumn{4}{|l|}{ QUANT5: } \\
\hline Reference & 1.0 & 1.0 & 1.0 \\
\hline \multicolumn{4}{|c|}{ Statistical tests (dietary variable modelled as five indicator variables) } \\
\hline Crude ( $\mathrm{P}$ value) & 0.0003 & $<0.0001$ & 0.0003 \\
\hline Adjusted (P value) & 0.004 & 0.003 & 0.09 \\
\hline
\end{tabular}

${ }^{*}$ Adjusted for maternal smoking, alcohol consumption, age, parity, height, pre-pregnant weight, length of education, and cohabitant status (see text).

†See text for definitions of six groups.

birth weight adjusted for gestational age all increased significantly across the four groups.

Risks of low birth weight and preterm delivery were significantly increased in the lowest group compared with the highest group, even after adjustment for potential confounding, with odds ratios of 3.57 (95\% confidence interval 1.14 to 11.14) for low birth weight and 3.60 (1.15 to 11.20) for preterm delivery, with the high intake group (FREQ3) as reference (table 7). The association between risk of intrauterine growth retardation and the dietary variable got much weaker and tended to be abolished after adjustment for confounding.

\section{Discussion}

Low consumption of seafood was a strong risk factor for preterm delivery and low birth weight. The associations were strongest below a daily intake of $0.15 \mathrm{~g}$ long chain $\mathrm{n}-3$ fatty acids or $15 \mathrm{~g}$ fish.

\section{Strengths and weaknesses}

Strengths of the study included that exposure data were collected in a concurrent fashion and long before

Table 5 Frequencies of hot meals and sandwiches containing fish consumed by the 3515 women who never ate salad with fish (seven were missing on one or both of the other two variables) and definition of groups for comparison

\begin{tabular}{|c|c|c|c|c|c|c|c|}
\hline \multirow[b]{2}{*}{ Hot meals } & \multicolumn{7}{|c|}{ Sandwiches } \\
\hline & Never & $<1$ per month & 1-3 per month & 1-2 per week & 3-6 per week & Every day & Total \\
\hline Never & $282^{*}$ & 143 & 186 & 99 & 14 & 4 & 728 \\
\hline$<1$ per month & 100 & $301 \dagger$ & 481 & 237 & 55 & 5 & 1179 \\
\hline 1-3 per month & 75 & 203 & $511 \ddagger$ & 383 & 97 & 11 & 1280 \\
\hline 1-2 per week & 17 & 33 & 58 & $141 \S$ & $51 \S$ & $8 \S$ & 308 \\
\hline 3-6 per week & 1 & 1 & 0 & $4 \S$ & $6 \S$ & $0 \S$ & 12 \\
\hline Every day & 0 & 0 & 0 & $0 \S$ & $0 \S$ & $0 \S$ & 0 \\
\hline Total & 475 & 681 & 1236 & 864 & 223 & 28 & 3507 \\
\hline
\end{tabular}

*Group FREQ0. †Group FREQ1. ‡Group FREQ2. §Group FREQ3. 
Table 6 Occurrences of low birth weight, preterm delivery, and intrauterine growth retardation, and mean birth weight, mean gestation length, and mean birth weight adjusted for length of gestation, according to frequency of fish intake

\begin{tabular}{|c|c|c|c|c|c|c|}
\hline \multirow[b]{2}{*}{ Group* } & \multicolumn{3}{|c|}{ Dichotomous outcomes (No (\%)) } & \multicolumn{3}{|c|}{ Continuous outcomes (mean (SD)) } \\
\hline & $\begin{array}{l}\text { Low birth } \\
\text { weight }\end{array}$ & $\begin{array}{l}\text { Preterm } \\
\text { delivery }\end{array}$ & $\begin{array}{l}\text { Intrauterine growth } \\
\text { retardation }\end{array}$ & Birth weight (g) & Gestation (days) & $\begin{array}{l}\text { Adjusted birth } \\
\text { weight }(\mathrm{g})\end{array}$ \\
\hline FREQ0 ( $n=282)$ & $20(7.1)$ & $20(7.1)$ & $23(8.2)$ & 3432 (589) & 278.8 (14.3) & $3466(490)$ \\
\hline FREQ1 $(n=301)$ & $12(4.0)$ & $14(4.7)$ & $27(9.0)$ & $3522(576)$ & $280.3(12.8)$ & $3513(554)$ \\
\hline FREQ2 $(n=511)$ & $13(2.5)$ & $18(3.5)$ & $30(5.9)$ & $3554(512)$ & $281.5(10.9)$ & $3512(451)$ \\
\hline FREQ3 $(n=210)$ & $4(1.9)$ & $4(1.9)$ & $13(6.2)$ & $3656(536)$ & $283.4(10.8)$ & $3561(486)$ \\
\hline \multicolumn{7}{|l|}{ Statistical tests } \\
\hline Between groups (P value) & $0.005 \dagger$ & $0.03 \dagger$ & $0.3 \dagger$ & $<0.001 \ddagger$ & $<0.001 \ddagger$ & $0.2 \ddagger$ \\
\hline Linear trend ( $\mathrm{P}$ value) & 0.001 & 0.003 & 0.2 & $<0.001$ & $<0.001$ & 0.04 \\
\hline
\end{tabular}

*See text and table 5 for definitions of comparison groups. $\nmid$ Pearson $\chi^{2}$. $\ddagger$ Analysis of variance.

occurrence of outcome among more than 8000 women, that exposure categories and other analytical conditions were decided a priori, and that analyses took account of nine potential confounding factors.

The main weakness of the study, as with any observational study, was the possibility of confounding that was not adjusted for. Adjustment had little impact on measures of association, but confounding by unmeasured factors cannot be ruled out.

Another weakness was that the assumed values for portion sizes, distributions of fish species in meals, and food contents of nutrients are only approximations to the true values. Imprecise estimates of quantified intake of $\mathrm{n}-3$ fatty acids are thus inevitable. Although this imprecision is unlikely to explain the steep decline in risk at the low end of the exposure distribution, it may contribute to the observed "bending" of the relation if imprecision increases with increasing exposure, a possibility that cannot be ruled out.

\section{Alternative strategy}

The alternative strategy was free of these assumptions as it simply used the questions on food frequency to define four groups with large differences in exposure; the questions had been shown to be strong and mutually independent predictors of $\mathrm{n}-3$ fatty acids measured in erythrocytes in the same population. ${ }^{15}$ It is therefore reassuring that this strategy corroborated the finding of a steep decline in risk across the lowest exposure groups, although with only four groups it was not pos-

Table 7 Crude and adjusted ${ }^{*}$ odds ratios $(95 \% \mathrm{Cl})$ for low birth weight, preterm delivery, and intrauterine growth retardation according to fish intake $(n=1159)$. The highest intake group (FREQ3) is used as reference

\begin{tabular}{|c|c|c|c|}
\hline Groupt & Low birth weight & Preterm delivery & $\begin{array}{l}\text { Intrauterine growth } \\
\text { retardation }\end{array}$ \\
\hline \multicolumn{4}{|l|}{ FREQ0: } \\
\hline Crude & 4.06 (1.34 to 12.01$)$ & 3.79 (1.26 to 11.38$)$ & 1.28 (0.61 to 2.71$)$ \\
\hline Adjusted & 3.57 (1.14 to 11.14$)$ & $3.60(1.15$ to 11.20$)$ & 1.01 (0.45 to 2.26$)$ \\
\hline \multicolumn{4}{|l|}{ FREQ1: } \\
\hline Crude & 1.60 (0.49 to 5.27$)$ & $2.34(0.75$ to 7.30$)$ & 1.44 (0.70 to 2.96$)$ \\
\hline Adjusted & 1.39 (0.41 to 4.67$)$ & 2.09 (0.66 to 6.62$)$ & 1.26 (0.59 to 2.66$)$ \\
\hline \multicolumn{4}{|l|}{ FREQ2: } \\
\hline Crude & $1.26(0.40$ to 3.96$)$ & 1.59 (0.52 to 4.85$)$ & 1.01 (0.51 to 2.03 ) \\
\hline Adjusted & 1.25 (0.39 to 3.94$)$ & 1.58 (0.52 to 4.83$)$ & 1.02 (0.50 to 2.08$)$ \\
\hline \multicolumn{4}{|l|}{ FREQ3: } \\
\hline Reference & 1.00 & 1.00 & 1.00 \\
\hline \multicolumn{4}{|c|}{ Statistical tests (dietary variable modelled as three indicator variables) } \\
\hline Crude ( $\mathrm{P}$ value) & 0.004 & 0.03 & 0.5 \\
\hline Adjusted (P value) & 0.02 & 0.06 & 0.8 \\
\hline
\end{tabular}

${ }^{*}$ Adjusted for maternal smoking, alcohol consumption, age, parity, height, pre-pregnant weight, length of education, and cohabitant status (see text).

†See text and table 5 for definitions of comparison groups.

\section{What is already known on this topic}

Long chain n-3 fatty acids in amounts above $2 \mathrm{~g}$ a day may delay spontaneous delivery and prevent recurrence of preterm delivery

Large studies have not been carried out to determine to what extent low consumption of n-3 fatty acids is a risk factor for preterm delivery

The dose-response relation has not been described

\section{What this study adds}

Low consumption of fish seems to be a strong risk factor for preterm delivery and low birth weight in Danish women

This relation is strongest below an estimated daily intake of $0.15 \mathrm{~g}$ long chain n-3 fatty acids or $15 \mathrm{~g}$ fish

sible to draw conclusions about levelling off at high exposures.

\section{Comparisons with other studies}

Overall, the findings agree with the randomised trials showing that consumption of fish oil in pregnancy can increase birth weight by prolonging gestation and reduce the risk of recurrence of preterm delivery. ${ }^{78}$ The finding that the dose-response relations were strong at low exposures corroborates two earlier studies. A reduction in early delivery was seen in women who had received only $0.1 \mathrm{~g} \mathrm{n}-3$ fatty acids (along with other substances) a day from week 20 of gestation. ${ }^{20-23}$ An association was seen between duration of pregnancy and a biomarker for intake of marine n-3 fatty acids (fatty acids measured in erythrocyte lipids) in Danish women, whereas no such association could be detected in Faroese women with a substantially higher intake, suggesting a stronger association at low exposures. ${ }^{24}$

A case-control study in the same population could not detect any association between seafood intake in pregnancy and risks of preterm birth ${ }^{25}$; unlike the present study, however, this study assessed dietary intake retrospectively after delivery, which may have distorted the results and led to the null finding.

Several observational studies have found associations between measures of maternal seafood intake and fetal growth rate. ${ }^{51-14}$ In the randomised trials, where fish oil was provided after week 16-20 of 
gestation, no effects were seen on fetal growth rate. ${ }^{78}$ The observational data could therefore possibly be explained either by effects of n-3 fatty acids exerted before week 16-20 or by effects of other substances in seafood. Our study could substantiate neither of these two possibilities, as the associations between seafood consumption in early pregnancy and fetal growth rate tended to disappear after adjustment for potential confounders.

Randomised controlled trials to examine the doseresponse relations between long chain n-3 fatty acids and timing of delivery and preterm risk are warranted.

NJS did part of this work during his current employment as chairman at the department of obstetrics and gynaecology, King Faisal Specialist Hospital and Research Center, Riyadh, Saudia Arabia. We thank Jakob Hjort, Ulrik Kesmodel, Janni Dalby Salvig, Kirsten Elise Højbjerg, Tine Brink Henriksen, and Morten Hedegaard for their help in producing the data set.

Contributors: SFO had the original idea for the study, formulated the questions about marine diets, was responsible for the statistical analyses, wrote the first draft of the paper, and is joint guarantor. NJS was responsible for initiating and building the cohort, contributed to the discussion of the results and the draft, and is joint guarantor.

Funding: Novo Nordisk Forskningsfond, Aage-Louis Hansens Fond, Danish National Research Foundation, March of Dimes Birth Defects Foundation, Danish Health Research Foundation, Egmont Fonden.

Competing interests: None declared.

1 Olsen SF, Joensen HD. High liveborn birth weights in the Faroes: a comparison between birth weights in the Faroes and in Denmark. J Epidemiol Community Health 1985;39:27-32

2 Olsen SF, Hansen HS, Sorensen TI, Jensen B, Secher NJ, Sommer S, et al Intake of marine fat, rich in (n-3)-polyunsaturated fatty acids, may increase birthweight by prolonging gestation. Lancet 1986;2:367-9.

3 Olsen SF, Hansen HS, Sorensen T, Jensen B, Secher NJ, Sommer S, et al. Hypothesis: dietary (N-3)-fatty acids prolong gestation in human beings. Prog Clin Biol Res 1987;242:51-6.

4 Olsen SF, Hansen HS. Marine fat, birthweight, and gestational age: a case report. Agents Actions 1987;22:373-4.

5 Olsen SF, Olsen J, Frische G. Does fish consumption during pregnancy increase fetal growth? A study of the size of the newborn, placental weigh and gestational age in relation to fish consumption during pregnancy. Int J Epidemiol 1990;19:971-7.

6 Olsen SF. Marine n-3 fatty acids ingested in pregnancy as a possible determinant of birth weight [correction appears in Am J Epidemiol 1994;139:856]. Epidemiol Rev 1993;15:399-413.
7 Olsen SF, Sorensen JD, Secher NJ, Hedegaard M, Henriksen TB, Hansen HS, et al. Randomised controlled trial of effect of fish-oil supplementation on pregnancy duration. Lancet 1992;339:1003-7.

8 Olsen SF, Secher NJ, Tabor A, Weber T, Walker JJ, Gluud C. Randomised clinical trials of fish oil supplementation in high risk pregnancies. $\mathrm{Br} \mathrm{J}$ Obstet Gynaecol 2000;107:382-95.

9 Olsen SF, Hansen HS, Jensen B. Fish oil versus arachis oil food supplementation in relation to pregnancy duration in rats. Prostaglandins Leukot Essent Fatty Acids 1990;40:255-60.

10 Baguma-Nibasheka M, Brenna JT, Nathanielsz PW. Delay of preterm delivery in sheep by omega-3 long-chain polyunsaturates. Biol Reprod 1999;60:698-701.

11 Olsen SF, Grandjean P, Weihe P, Videro T. Frequency of seafood intake in pregnancy as a determinant of birth weight: evidence for a dose dependent relationship. J Epidemiol Community Health 1993;47:436-40.

12 Olsen SF. Further on the association between retarded foetal growth and adult cardiovascular disease. Could low intake of marine diets be a common cause? J Clin Epidemiol 1994;47:565-9.

13 Dar E, Kanarek MS, Anderson HA, Sonzognu WC. Fish consumption and reproductive outcomes in Green Bay Wisconsin. Environ Res 1992;59:189-201.

14 Dagnelie PC, van Staveren WA, van Klaveren JD, Burema J. Do children on macrobiotic diets show catch-up growth? A population-based cross-sectional study in children aged 0-8 years. Eur J Clin Nutr $1988 ; 42: 1007-16$

15 Olsen SF, Hansen HS, Sandström M, Jensen B. Erythrocyte levels compared with reported dietary intake of marine n-3 fatty acids in pregnant women. Br J Nutr 1995;73:387-95.

16 Kesmodel U, Olsen SF, Secher NJ. Does alcohol increase the risk of preterm delivery? Epidemiology 2000;11:512-8

17 Andersen LT, Jensen H, Haraldsdottir J. Typiske vægte for madvarer Scand J Nutr 1996;40:S129-52.

18 Levnedsmiddelstyrelsen. Levnedsmiddeltabeller (The composition of foods). Copenhagen: Levnedsmiddelstyrelsen, 1996.

19 Secher NJ, Hansen PK, Lenstrup C, Pedersen-Bjergaard L, Eriksen PS, Thomsen BL, et al. Birthweight-for-gestational age charts based on early ultrasound estimation of gestational age. $\mathrm{Br} J$ Obstet Gynaecol 1986;93:128-34

20 Olsen SF, Secher NJ. A possible preventive effect of low-dose fish oil on early delivery and pre-eclampsia: indications from a 50-year-old controlled trial. Br J Nutr 1990;64:599-609.

21 People's League of Health. Nutrition of expectant and nursing mothers. Lancet 1942;ii:10-2.

22 People's League of Health. The nutrition of expectant and nursing mothers in relation to maternal and infant mortality and morbidity. $J$ Obste Gynaecol Br Emp 1946;53:498-509.

23 People's League of Health. Nutrition of expectant and nursing mothers. BMJ 1942;ii:77-8.

24 Olsen SF, Hansen HS, Sommer S, Jensen B, Sørensen TIA, Secher NJ, et al. Gestational age in relation to marine n-3 fatty acids in maternal erythrocytes: a study of women in the Faroe Islands and Denmark. Am J Obstel Gynecol 1991;164:1203-9.

25 Kesmodel U, Olsen SF, Salvig JD. Marine n-3 fatty acid and calcium intake in relation to pregnancy induced hypertension, intrauterine growth retardation, and preterm delivery: a case-control study. Acta Obstet Gynecol Scand 1997;76:38-44.

(Accepted 5 November 2001) 